\section{Change in peak expiratory flow rate after the head-tilt/chin-lift maneuver among young, healthy, and conscious volunteers}

\author{
Sion Jo' , Jae Baek Lee ${ }^{1,2}$, Youngho Jin ${ }^{1,2}$, Taeoh Jeong ${ }^{1,2}$, Jaechol Yoon ${ }^{1,2}$, \\ Boyoung Park ${ }^{3}$
}

'Department of Emergency Medicine, Research Institute of Clinical Medicine of Chonbuk National University and Biomedical Research Institute of Chonbuk National University Hospital, Jeonju, Korea ${ }^{2}$ Department of Emergency Medicine, College of Medicine, Chonbuk National University, Jeonju, Korea ${ }^{3}$ Department of Medicine, Hanyang University College of Medicine, Seoul, Korea

Objective The head-tilt/chin-lift $(\mathrm{HT} / \mathrm{CL})$ is a simple, routinely used maneuver to open the upper airway. Changes in the peak expiratory flow rate (PEFR) before and after the HT/CL maneuver have not been evaluated among conscious volunteers who are regarded as a control cohort.

Methods Sixty healthy 20-year-old volunteers (30 males and 30 females) were enrolled. The supine position was defined as the position at which the ear-eye line was at a $10^{\circ}$ angle to the horizontal. The HT/CL position was defined as the position at which the ear-eye line was at a $25^{\circ}$ angle to the horizontal. PEFR was measured using a hand-held device with the subject in the supine position (pre-PEFR) and HT/CL position (post-PEFR), respectively. One set was defined as these two measurements. Five sets of measurements were performed on each subject (300 sets). The set with the maximal and minimal difference between pre-PEFR and post-PEFR were excluded from the analysis. We used a paired t-test to compare the mean pre-PEFR and post-PEFR values for the entire group and subgroups divided by sex, height, body weight, body mass index and response status.

Results Overall, 360 measurements (180 sets) were analyzed. The mean pre-PEFR and post-PEFR were $316.1 \pm 87.6$ and $346.5 \pm 94.7 \mathrm{~L} / \mathrm{min}$, respectively. Further, significant differences were observed for sex, height, body weight, and body mass index. In 10 subjects, post-PEFR was lower than pre-PEFR.

Conclusion PEFR increased by $9.6 \%$ after the $\mathrm{HT} / \mathrm{CL}$ maneuver in young conscious subjects, but some subjects showed decreased PEFR after the HT/CL maneuver.

Keywords Peak expiratory flow rate; Head-tilt/chin lift; Airway management

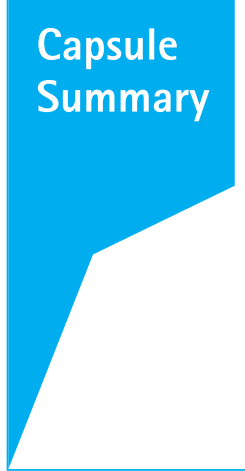

What is already known

The head-tilt/chin-lift (HT/CL) is a simple, routinely used maneuver to open the upper airway. Changes in peak expiratory flow rate (PEFR) before and after the $\mathrm{HT} / \mathrm{CL}$ maneuver have not been evaluated among conscious volunteers who are regarded as a control cohort.

What is new in the current study

PEFR increased by $9.6 \%$ after the HT/CL maneuver in young conscious subjects, but some subjects showed decreased PEFR after the HT/CL maneuver.
This is an Open Access article distributed
under the terms of the Creative Commons
Attribution Non-Commercial License (http:/
creativecommons.org/licenses/by-nc/4.0/).

This is an Open Access article distributed
under the terms of the Creative Commons
Attribution Non-Commercial License (http://
creativecommons.org/licenses/by-nc/4.0/).

This is an Open Access article distributed
under the terms of the Creative Commons
Attribution Non-Commercial License (http://
creativecommons.org/licenses/by-nc/4.0/).

Received: 30 January 2018 Revised: 19 March 2018

Accepted: 6 April 2018

Correspondence to: Jae Baek Lee Department of Emergency Medicine, Research Institute of Clinical Medicine of Chonbuk National University and Biomedical Research Institute of Chonbuk National University Hospital, 20 Geonji-ro, Deokjin-gu, Jeonju 54907, Korea

E-mail: baeklee@jbnu.ac.kr ORCID http://orcid.org/0000-0002-6317-3174

How to cite this article: Jo $S$, Lee JB, Jin Y, Jeong T, Yoon J, Park B. Change in peak expiratory flow rate after the head-tilt/chin-lift maneuver among young, healthy, and conscious volunteers. Clin Exp Emerg Med 2019;6(1):36-42. 


\section{INTRODUCTION}

Unconscious patients can present with airway obstruction without the presence of foreign bodies, injured tissue, blood, or secretions. In such cases, prolapse of the relaxed tongue and soft palate onto the posterior pharynx after muscular tone loss is considered the main mechanism of obstruction. ${ }^{1-3}$ Respiratory distress is inevitable if the airway obstruction is not resolved promptly. Therefore, the rescuer should attempt to maintain patency of the airway.

To open the airway and elevate the relaxed tongue, two simple maneuvers can be applied. The head-tilt/chin-lift $(\mathrm{HT} / \mathrm{CL})$ is the primary maneuver, and it is used in most cases unless head or neck injury is suspected in the patient. ${ }^{4,5}$ The jaw-thrust maneuver is reserved for patients who present with head or neck injury. ${ }^{6,7}$ Both maneuvers have been adopted by current resuscitation guidelines $_{1}^{8-10}$ and have been used and taught worldwide for decades.

Despite the popularity and simplicity of the $\mathrm{HT} / \mathrm{CL}$, little is known regarding its physiologic effects. Furthermore, the last studies evaluating these effects were published decades ago, and patients enrolled in these studies were anesthetized to ensure a controlled environment. ${ }^{11-13}$

Nevertheless, the basic physiologic effects of the HT/CL can be easily measured in healthy subjects. To the best of our knowledge, no studies have assessed the extent to which $\mathrm{HT} / \mathrm{CL}$ increases airflow, or whether it even does so at all. Such data would help the $\mathrm{HT} / \mathrm{CL}$ regain relevance for use in conscious patients, as it has with unconscious patients undergoing anesthesia for decades. Thus, this study aimed to evaluate basic physiologic data obtained from measuring the percentage change in peak expiratory flow rate (PEFR) before and after the HT/CL maneuver in healthy subjects. We hypothesized that there would be a significant PEFR increase after $\mathrm{HT} / \mathrm{CL}$ in healthy conscious volunteers.

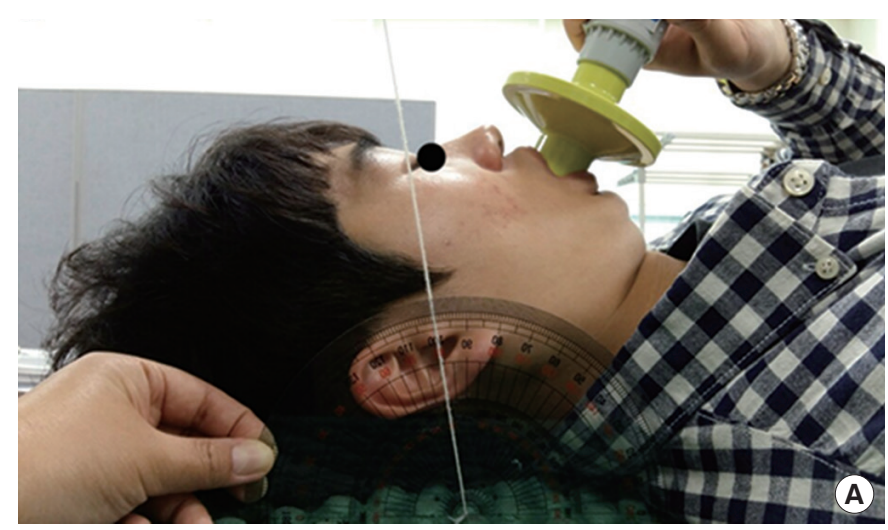

\section{METHODS}

\section{Ethics}

This study met local legal and institutional requirements and generally accepted ethical principles such as those set out in the Nuremberg Code, the Belmont Report, and the Declaration of Helsinki. This study was approved by the institutional review board of Chonbuk National University Hospital (2016-09-013). After a thorough face-to-face explanation of study procedures using a visual supplement, all participants freely provided written informed consent for enrollment. The present study was supported by funding from the Biomedical Research Institute, Chonbuk National University Hospital.

\section{Selection of participants}

Sixty healthy subjects (30 males and 30 females) were enrolled between March 1 and August 31, 2017. All subjects were aged 20 years and were students at Chonbuk National University. Exclusion criteria were as follows: 1) having a conflict of interest related to the authors' affiliation with the School of Medicine, as was the case with medical and nursing students; 2) concurrent upper or lower respiratory infection such as pharyngitis, bronchitis or pneumonia; 3) chronic airway diseases such as asthma or chronic obstructive pulmonary disease; 4) pulmonary tuberculosis or related complications; 5) body mass index (BMI) $\geq 25 \mathrm{~kg} / \mathrm{m}^{2}$ (obese) or $\leq 18.5 \mathrm{~kg} / \mathrm{m}^{2}$ (underweight) ${ }^{14} ; 6$ ) comorbidities such as hypertension, diabetes mellitus, chronic liver disease, chronic renal disease, cardiovascular disease, cerebrovascular disease or malignancy; 7) known sleep apnea with possible distortion of the upper respiratory airway; 8) conditions limiting the adoption of a supine position such as scoliosis; 9) conditions limiting the adoption of the HT/CL position; and 10) other conditions deemed as inappropriate for study participation by the authors.

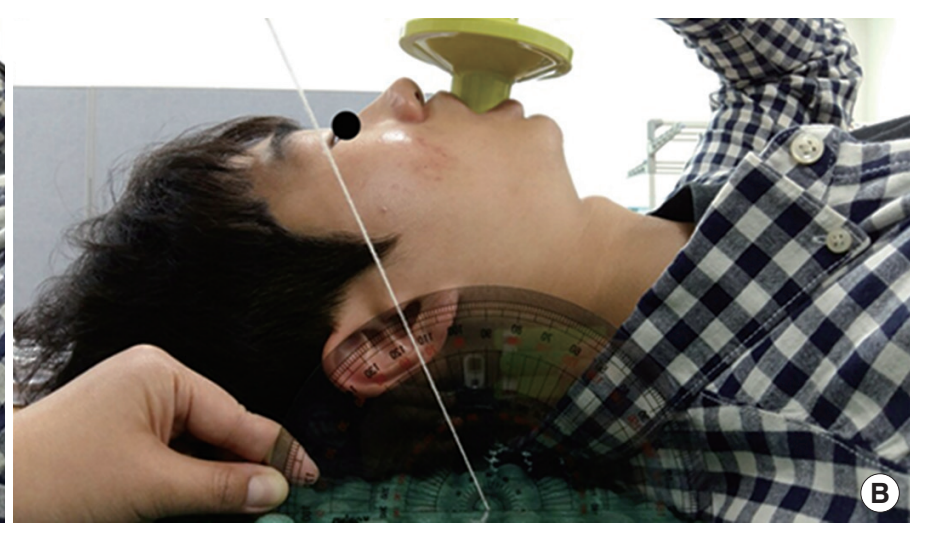

Fig. 1. (A) Peak expiratory flow rate before head-tilt/chin-lift (HT/CL) position (supine position) and (B) peak expiratory flow rate after $\mathrm{HT} / \mathrm{CL}$ position (HT/CL position). The participant consented to being displayed in the figure. 
The equivalence limit and percent change in standard deviation were set at $0.5(50 \%)$ and 1 (100\%), respectively. We calculated that 30 patients were needed for a power of $90 \%$ and alpha error of 0.15 . Because reference values of PEFR differed according to sex, we determined a total of 60 participants were needed, 30 males and 30 females. ${ }^{15}$

\section{Procedures and measurements}

PEFR is defined as the maximum speed of expiration, as measured by a peak flowmeter. By definition, PEFR cannot be measured in unconscious subjects.

PEFR was measured using MicroPeakTM ${ }^{\circledR}$ (CareFusion; The Crescent, Jays Close Basingstoke, UK). The measurable range of the device was between 60 and $900 \mathrm{~L} / \mathrm{min}$ with scale increments of $10 \mathrm{~L} / \mathrm{min}$. The PEFR values were rounded to the nearest tenth.

The supine position was defined as the position at which the ear-eye line was at a $10^{\circ}$ angle to the horizontal (Fig. 1). The HT/ $\mathrm{CL}$ position was defined as the position at which the ear-eye line was at a $25^{\circ}$ angle to the horizontal (Fig. 1). Subjects were placed in supine and $\mathrm{HT} / \mathrm{CL}$ positions by the authors. Authors encouraged the subjects to breathe out with maximal effort as PEFR was measured. Sex, height, and body weight were collected along with PEFR variables. Height and body weight were measured at the study site. Each subject was provided a new mouthpiece that was used throughout the whole measurment.

\section{PEFR measurement protocol}

PEFR was measured using the following steps. Steps 2 to 5 were repeated five times to obtain five sets of measurements for the supine and HT/CL positions: 1) the study participant was placed in the supine position and was asked to remain at rest for 5 minutes. 2) PEFR was measured in the supine position (e.g., supine no. 1). 3) The subject was placed in the HT/CL position and was asked to remain at rest for 1 minute. 4) PEFR was measured at the HT/CL position (e.g., HT/CL no. 1). 5) The subject was placed in the supine position and was asked to remain at rest for 1 minute.

\section{Statistical analysis}

Continuous data are presented as median and interquartile range (IQR) or mean and standard deviation. Discrete data are presented as counts and percentages. To compare baseline characteristics between male and female subjects, or between responders and non-responders, the Student's t-test was used for normally distributed variables and the Mann-Whitney U-test was used for non-normally distributed variables. For categorical data, the chisquare test or the chi-square test with Fisher exact test for $2 \times 2$ tables was used. To compare mean PEFR before HT/CL (pre-PEFR) and PEFR after HT/CL (post-PEFR) values as a whole and by sex, height, body weight, BMI and response status, we used the paired t-test under assumption that values were normally distributed if the number was above 30. If the number was below 30, the Kolmogorov-Smirnov test was performed to check the normal distribution. The participants who showed decreased post-PEFR values compared to pre-PEFR values were grouped as non-responders. The results were considered significant at a threshold of $\mathrm{P}<0.05$ (two-tailed). All statistical analyses were conducted using Stata ver. 11.1 (StataCorp., College Station, TX, USA) and SAS ver. 9.1 (SAS Institute Inc., Cary, NC, USA).

\section{RESULTS}

\section{Patient demographics}

Overall, 60 subjects were enrolled, of whom 30 were male. A total of 360 measurements were collected. Subjects had a median height of $168(I Q R, 162$ to 176) cm and median body weight of 61.5 (IQR, 52.5 to 67.5) kg. The median BMI was 21.3 (IQR, 19.8 to 23.0$) \mathrm{kg} / \mathrm{m}^{2}$. Height, body weight and BMI were significantly lower in females than in males $(\mathrm{P}<0.001)$ (Table 1$)$.

\section{Change in PEFR after HT/CL}

Fig. 2 shows the main results of the present study. Overall, postPFER was significantly higher than pre-PEFR (346.5 \pm 94.7 vs. $316.1 \pm 87.6 \mathrm{~L} / \mathrm{min}$, respectively, $\mathrm{P}<0.001$, difference $30.4 \mathrm{~L} / \mathrm{min}$, with a percentage change in pre-PEFR of $9.6 \%$ ).

Post-PEFR was significantly higher than pre-PEFR in the male and female groups (male subjects: $414.0 \pm 78.4$ vs. $368.4 \pm 85.4 \mathrm{~L}$ / min, respectively, $\mathrm{P}<0.001$, difference $45.6 \mathrm{~L} / \mathrm{min}$, with a percentage change in pre-PEFR of $12.4 \%$; female subjects: $279.0 \pm 51.9$ vs. $263.7 \pm 51.0 \mathrm{~L} / \mathrm{min}$, respectively, $\mathrm{P}<0.001$, difference $15.3 \mathrm{~L} / \mathrm{min}$, with a percentage change in pre-PEFR of 5.8\%).

Among the patients with a height greater than the median value (the taller group), post-PEFR was significantly higher than pre-PEFR. Further, post-PEFR was significantly higher among subjects with a height lower than the median value (the shorter group) (taller group: $410.8 \pm 82.1$ vs. $363.1 \pm 90.3$ L/min, respectively, $\mathrm{P}<0.001$, difference $47.7 \mathrm{~L} / \mathrm{min}$, with a percentage change

Table 1. Baseline characteristics of the subjects

\begin{tabular}{lccc}
\hline Variable & \multicolumn{1}{c}{ Total } & Male & Female \\
\hline Number & $60(100)$ & $30(50)$ & $30(50)$ \\
Height $(\mathrm{cm})$ & $168(162-176)$ & $175(173-178)$ & $162(158-167)$ \\
Body weight $(\mathrm{kg})$ & $61.5(52.5-67.5)$ & $67.0(64.0-73.0)$ & $52.5(50-60.0)$ \\
Body mass index $\left(\mathrm{kg} / \mathrm{m}^{2}\right)$ & $21.3(19.8-23.0)$ & $22.1(20.7-23.7)$ & $20.0(19.0-21.7)$ \\
\hline
\end{tabular}

Values are presented as number (\%) or median (interquartile range). 


\begin{tabular}{|c|c|c|c|c|c|c|}
\hline & & Mean (L/min) & SD & P-value & Difference & $\%$ to pre \\
\hline \multirow[t]{2}{*}{ Total $(n=60)$} & Pre-PEFR & 316.1 & 87.6 & $<0.001$ & 30.4 & 9.6 \\
\hline & Post-PEFR & 346.5 & 94.7 & & & \\
\hline \multirow[t]{2}{*}{ Male $(n=30)$} & Pre-PEFR & 368.4 & 85.4 & $<0.001$ & 45.6 & 12.4 \\
\hline & Post-PEFR & 414.0 & 78.4 & & & \\
\hline \multirow[t]{2}{*}{ Female $(n=30)$} & Pre-PEFR & 263.7 & 51.0 & $<0.001$ & 15.3 & 5.8 \\
\hline & Post-PEFR & 279.0 & 51.9 & & & \\
\hline \multirow{2}{*}{$\begin{array}{l}\text { Height } \geq \text { median } \\
\qquad(168.0 \mathrm{~cm})(n=30)\end{array}$} & Pre-PEFR & 363.1 & 90.3 & $<0.001$ & 47.7 & 13.1 \\
\hline & Post-PEFR & 410.8 & 82.1 & & & \\
\hline \multirow[t]{2}{*}{ Height < median $(n=30)$} & Pre-PEFR & 269.0 & 53.0 & $<0.001$ & 13.2 & 4.9 \\
\hline & Post-PEFR & 282.2 & 54.3 & & & \\
\hline \multirow{2}{*}{$\begin{array}{l}\text { Body weight } \geq \text { median } \\
(61.5 \mathrm{~kg})(n=30)\end{array}$} & Pre-PEFR & 355.7 & 91.1 & $<0.001$ & 42.0 & 11.8 \\
\hline & Post-PEFR & 397.7 & 89.6 & & & \\
\hline \multirow{2}{*}{$\begin{array}{l}\text { Body weight }<\text { median } \\
(n=30)\end{array}$} & Pre-PEFR & 276.4 & 63.0 & $<0.001$ & 18.9 & 6.8 \\
\hline & Post-PEFR & 295.3 & 68.7 & & & \\
\hline \multirow{2}{*}{$\begin{array}{l}\text { Body mass index } \geq \text { median } \\
(21.3)(n=30)\end{array}$} & Pre-PEFR & 321.2 & 84.8 & $<0.001$ & 35.6 & 11.1 \\
\hline & Post-PEFR & 356.8 & 92.2 & & & \\
\hline \multirow{2}{*}{$\begin{array}{l}\text { Body mass index }<\text { median } \\
(n=30)\end{array}$} & Pre-PEFR & 310.9 & 90.6 & $<0.001$ & 25.3 & 8.1 \\
\hline & Post-PEFR & 336.2 & 96.6 & & & \\
\hline \multirow{2}{*}{$\begin{array}{l}\text { Responder } \\
\text { (PEFR difference } \geq 0)(n=50)\end{array}$} & Pre-PEFR & 312.9 & 88.7 & $<0.001$ & 39.0 & 12.5 \\
\hline & Post-PEFR & 351.9 & 97.0 & & & \\
\hline \multirow{2}{*}{$\begin{array}{l}\text { Non-responder } \\
(\text { PEFR difference < } 0)(n=10)\end{array}$} & Pre-PEFR & 331.7 & 81.8 & 0.008 & -12.4 & -3.7 \\
\hline & Post-PEFR & 319.3 & 78.3 & & & \\
\hline
\end{tabular}

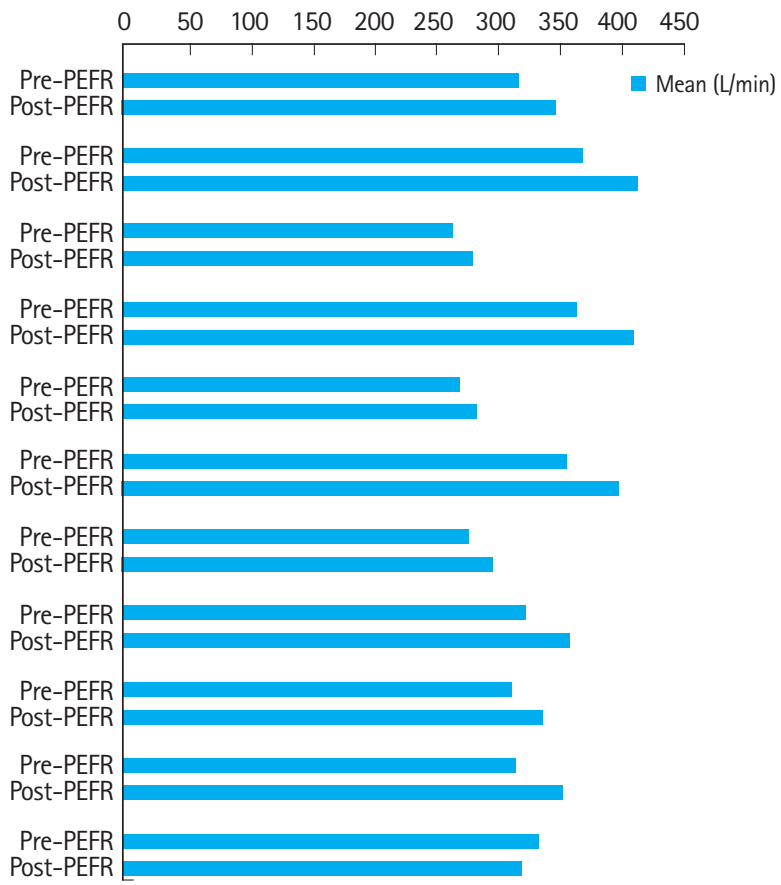

Fig. 2. Main results of the present study. A paired t-test was used to compare peak expiratory flow rate before head-tilt/chin-lift (pre-PEFR) and peak expiratory flow rate after head-tilt/chin-lift (post-PEFR). SD, standard deviation.

in pre-PEFR of $13.1 \%$; shorter group: $282.2 \pm 54.3$ vs. $269.0 \pm 53.0$ L/min, respectively, $\mathrm{P}<0.001$, difference $13.2 \mathrm{~L} / \mathrm{min}$, with a percentage change in pre-PEFR of 4.9\%).

Among subjects with body weight greater than the median value (higher body weight group), post-PEFR was significantly higher than pre-PEFR. This was similar among subjects with body weight lower than the median value (lower body weight group) (higher body weight group: $397.7 \pm 89.6$ vs. $355.7 \pm 91.1 \mathrm{~L} / \mathrm{min}$, respectively, $\mathrm{P}<0.001$, difference $42.0 \mathrm{~L} / \mathrm{min}$, percentage change in pre-PEFR of $11.8 \%$; lower body weight group: $295.3 \pm 68.7 \mathrm{vs.}$ $276.4 \pm 63.0 \mathrm{~L} / \mathrm{min}, \mathrm{P}<0.001$, difference $18.9 \mathrm{~L} / \mathrm{min}$, percentage change in pre-PEFR of 6.8\%).

Post-PEFR was significantly higher than pre-PEFR among subjects with BMI greater than the median value (higher BMI group). This was similar among subjects with BMI lower than the median value (lower BMl group) (higher BMl group: $356.8 \pm 92.2$ vs. $321.2 \pm$ $84.8 \mathrm{~L} / \mathrm{min}, \mathrm{P}<0.001$, difference $35.6 \mathrm{~L} / \mathrm{min}$, percentage change in pre-PEFR, $11.1 \%$; lower BMI group: $336.2 \pm 96.6$ vs. $310.9 \pm 90.6$ $\mathrm{L} / \mathrm{min}, \mathrm{P}<0.001$, difference $25.3 \mathrm{~L} / \mathrm{min}$, percentage change in prePEFR, 8.1\%).

\section{Non-responders after $\mathrm{HT} / \mathrm{CL}$}

Ten subjects showed decreased post-PEFR values compared to pre-PEFR values and were grouped as non-responders, with the remaining 50 subjects grouped as responders. In the responder
Table 2. Comparison of baseline characteristics between head-tilt/chinlift responders and non-responders

\begin{tabular}{lccc}
\hline Variable & $\begin{array}{c}\text { Responder } \\
50(83.3)\end{array}$ & $\begin{array}{c}\text { Non-responder } \\
10(16.7)\end{array}$ & P-value \\
\hline Male & $27(54.0)$ & $3(30.0)$ & 0.166 \\
Height $(\mathrm{cm})$ & $170(162-177)$ & $164(162-167)$ & 0.095 \\
Body weight $(\mathrm{kg})$ & $63.5(53.0-68.0)$ & $58.5(51.0-61.0)$ & 0.237 \\
Body mass index $\left(\mathrm{kg} / \mathrm{m}^{2}\right)$ & $21.3(19.8-23.0)$ & $21.4(19.4-22.9)$ & 0.890 \\
\hline
\end{tabular}

Values are presented as number (\%) or median (interquartile range). P-value was calculated using Mann-Whitney U-test.

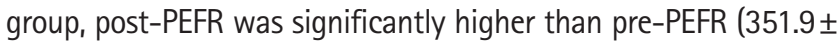
97.0 vs. $312.9 \pm 88.7 \mathrm{~L} / \mathrm{min}, \mathrm{P}<0.001$, difference $39.0 \mathrm{~L} / \mathrm{min}$, percentage change in pre-PEFR, 12.5\%). In the non-responder group, post-PEFR was significantly lower than pre-PEFR $(319.3 \pm 78.3 \mathrm{vs}$. $331.7 \pm 81.8 \mathrm{~L} / \mathrm{min}, \mathrm{P}=0.008$; difference, $-12.4 \mathrm{~L} / \mathrm{min}$; percentage change in pre-PEFR, $-3.7 \%$ ).

Baseline characteristics were compared between the responder and non-responder groups (Table 2). Height was slightly greater in the responder group $(P=0.095)$, but sex, body weight and $B M I$ were not significantly different.

\section{DISCUSSION}

Post-PEFR was significantly higher than pre-PEFR in 20-year-old healthy participants. The difference was $30.4 \mathrm{~L} / \mathrm{min}$, and the per- 

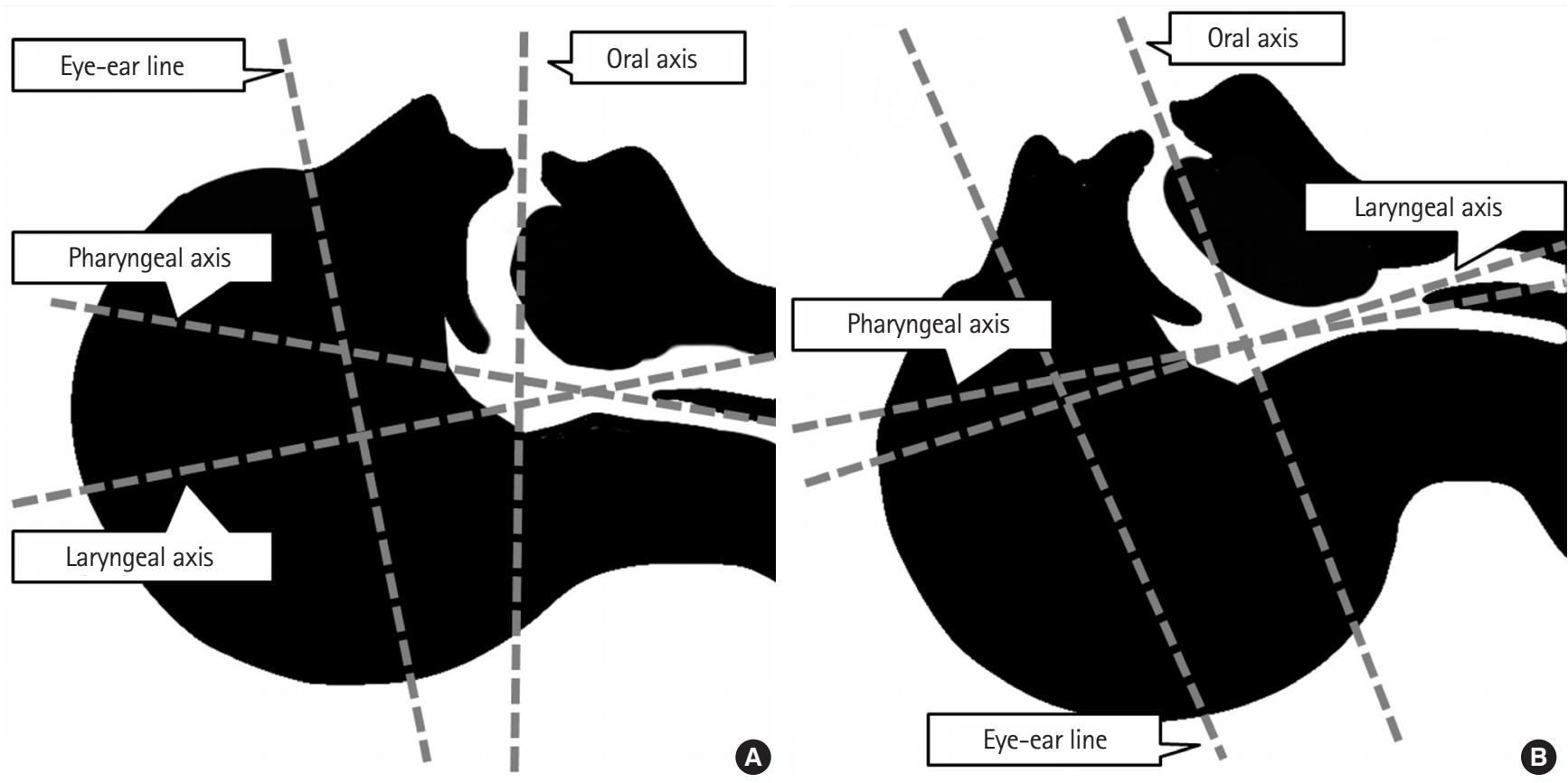

Fig. 3. Three axes of the upper airway. (A) The supine position and (B) the head-tilt/chin-lift position.

centage change in pre-PEFR was $9.6 \%$. When categorized by sex, height, body weight and BMI, significant differences between pre-PEFR and post-PEFR remained.

Upper airway obstructions can occur anywhere from the mouth through the length of the trachea, including the nasopharynx and larynx. Mechanisms are as follows: 1) intraluminal compromise secondary to intrinsic or extrinsic compression by a tumor; 2) granulation tissue or calcium deposition; 3 ) airway wall thinning or collapse from cartilage disorders or tracheobronchomalacia; 4) airway wall edema; and 5) aspiration of material such as foreign body, blood or vomitus. However, among unconscious patients, the main mechanism of upper airway obstruction is prolapse of the relaxed tongue and soft palate onto the posterior pharynx after muscular tone loss. ${ }^{1-3}$ Studies investigating this phenomenon date back to the 1950s.

In a previous study, among 50 anesthetized patients who were breathing naturally, bending of the neck such that the chin was on the chest led to a complete blockage of air passage through the throat. Pulling the chin up resolved the airway obstruction in $50 \%$ of the patients. The remaining 50\% of the patients required the jaw-thrust maneuver, insertion of an oropharyngeal airway, or both..$^{11}$ Based on these data, in 1959, Safar et al. ${ }^{12}$ suggested opening the airway using the thumb-jaw-lift method or the twohand jaw-lift method. Thereafter, opening the airway became the first step during artificial ventilation to maintain airway patency and facilitate sufficient ventilation.
In 1976, Guildner ${ }^{14}$ investigated three techniques in 120 patients who were anesthetized for elective surgery: neck lift, chin lift, and jaw thrust. After subjective evaluation of the effectiveness of these techniques, chin-lift was found to be the most effective (90.8\%), followed by jaw thrust (78\%) and neck lift (39.2\%). On tidal volume evaluation using a Wright respirometer, chin-lift was found to be the most effective (> $400 \mathrm{~mL}, 70 \%$; 250-400 mL, 23.3\%; 50-250 mL, 6.7\%), followed by jaw thrust (> $400 \mathrm{~mL}, 63.3 \%$; 250-400 mL, 23.3\%; 50-250 mL, 10\%; 0-50 $\mathrm{mL}, 3.4 \%$ ) and neck lift (> $400 \mathrm{~mL}, 6.7 \% ; 250-400 \mathrm{~mL}, 20 \%$; 50$250 \mathrm{~mL}, 30 \%$; 0-50 mL, 43.3\%).

Surprisingly, although airway opening maneuvers are applied and taught worldwide, the physiologic changes that occur with these maneuvers have not been evaluated. Simple points such as the optimal degree of HT/CL position and dose (or angle) dependency are still unclear. Even easily measurable pulmonary function test parameters have not been investigated. Notably, airway patency following the $\mathrm{HT} / \mathrm{CL}$ maneuver is verified by chest rise rather than a specific $\mathrm{HT} / \mathrm{CL}$ angle. Thus, the present study aimed to evaluate the percentage change in PEFR before and after HT/ $\mathrm{CL}$. Among 60 healthy subjects, post-PEFR was significantly increased compared to pre-PEFR. The difference was $30.4 \mathrm{~L} / \mathrm{min}$, and the percentage change in pre-PEFR was 9.6\%. When categorized by sex, height, body weight and $\mathrm{BMI}$, significant differences between pre-PEFR and post-PEFR remained.

The results of the present study are notable because airway 
obstruction in the study participants was not due to a prolapsed tongue or soft palate, as in unconscious patients. Expiratory flow would not be expected to change, since theoretically there was no change in the diameter and length of the upper airway after the $\mathrm{HT} / \mathrm{CL}$ maneuver. The only movement during the maneuver was an angular motion at the joint between head and neck.

The upper airway is a kinked tube, rather than a straight one. There are three axes in the upper airway: the oral axis, pharyngeal axis, and laryngeal axis (Fig. 3). Expiratory airflow from the trachea and larynx should change direction at the laryngeal-hypopharynx (intersection point between laryngeal axis and pharyngeal axis) and oropharynx-oral cavity (intersection point between pharyngeal axis and oral axis) junctions. Thereafter, air escapes completely through the mouth. In the present study, the pre-PEFR position (supine position) was defined as the position at which the ear-eye line was at a $10^{\circ}$ angle to the horizontal. The postPEFR position (HT/CL position) was defined as the position at which the ear-eye line was at a $25^{\circ}$ angle to the horizontal (Fig. 1). If we assume that the expiratory flow from the trachea was parallel to the horizontal plane, the estimated total resistance in expiratory airflow due to kinking would be $\sin 80^{\circ}(0.984)$ in the pre-PEFR position and $\sin 65^{\circ}(0.906)$ in the post-PEFR position. If the tube were straight, the resistance due to kinking would be $\sin 0^{\circ}(0)$. Thus, the theoretical percentage change in PEFR is $8.9 \%$. This is very close to the measured percent change in PEFR of $9.6 \%$, although the actual sin values at the two junctions were not accounted for comprehensively. Additionally, as the kinked upper airway unfolded, some of the turbulent flow may have become laminar. The authors presume that unfolding of the kinked upper airway after the HT/CL would result in increased PEFR. This proposed mechanism provides yet another reason to perform the $\mathrm{HT} / \mathrm{CL}$ in unconscious patients. Although the present study did not include unconscious patients, the proposed mechanism may also be applicable to unconscious patients, since the kinked upper airway would unfold similarly in conscious and unconscious patients. Considering that a prolapsed tongue would be elevated by the HT/CL maneuver, it would be expected that the PEFR change would be greater in unconscious than in conscious subjects.

Notably, a decreased PEFR after the HT/CL was observed in a substantial number of participants (16.7\%). This finding is unexpected given the potential mechanisms suggested by the authors. However, it cannot be concluded that $\mathrm{HT} / \mathrm{CL}$ is not beneficial for these subjects. A HT/CL angle of $15^{\circ}$ may have been insufficient in those subjects. Increasing the angle $>15^{\circ}$ may have resulted in an increased post-PEFR compared to pre-PEFR (i.e., $30^{\circ}$ ). There are a few other possible explanations for this finding. First, when the kinked upper airway was unfolded by the $\mathrm{HT} / \mathrm{CL}$, a narrowing at a specific site of the upper airway may have occur in some subjects. Flexibility of the upper airway is particularly low in those with short necks, and unfolding could have resulted in tube narrowing in such subjects. Second, subjects who engage in abdominal breathing may have had difficulties exhaling with maximal effort after the HT/CL compared to those who engage in thoracic breathing. However, there is no data to support these hypotheses to date, and they should be evaluated further. Some parameters such as hyoid-mental distance and thyroid-to-floor or mouth distance may be helpful. It has been proposed that differences in these distances may affect the ability of the HT/CL to open the airway in certain patients.

This study had some limitations. The mean post-PEFR values in males and females were much lower than the reference values for both sexes at 20 years old (approximately $550 \mathrm{~L} / \mathrm{min}$ in males, $420 \mathrm{~L} / \mathrm{min}$ in females). This may be because the supine position inhibits overall body motion, thus limiting the maximal expiratory effort. Second, the authors positioned the subjects without radiology-assisted methods. A simple radiologic evaluation such as a lateral neck radiograph would clarify the surprising findings of the present study regarding the effect of the three axes of the upper airway on expiratory flow. Third, subjects determine when they have provided maximum respiratory effort; there is no objective method to measure maximal effort. However, the authors encouraged subjects to try their hardest during each measurement. Fourth, we did not evaluate the anatomy of the patients' airway via endoscopy or radiological imaging at any point during the study. The exclusion criteria of the present study were very detailed; however, some conditions such as undetected congenital or acquired abnormalities could have biased the results. Fifth, it should be noted that using the $\mathrm{HT} / \mathrm{CL}$ in combination with artificial ventilation techniques such as bag-valve ventilation is a passive method of ventilation. In the present study, PEFRs before and after the $\mathrm{HT} / \mathrm{CL}$ maneuver were measured using active expiration; it is likely that the value would change if measured using passive methods of expiration such as bag-valve ventilation. Sixth, the sample size was relatively small. Nonetheless, it was sufficient to allow for significant findings. Additionally, the baseline characteristics of the subjects were similar to the values of body height, weight and BMI reported by national surveys for individuals aged between 20 and 23 years. ${ }^{16}$

The percentage change in PEFR was 9.6\% after the HT/CL maneuver in healthy, conscious subjects. Unfolding of the kinked upper airway is a potential underlying mechanism. Notably, some subjects showed decreased PEFR after the HT/CL maneuver. 


\section{CONFLICT OF INTEREST}

No potential conflict of interest relevant to this article was reported.

\section{ACKNOWLEDGMENTS}

This paper was supported by funding from the Biomedical Research Institute, Chonbuk National University Hospital. We would like to thank Yujin Jo, who assisted the data collection.

\section{REFERENCES}

1. Safar P. Failure of manual respiration. J Appl Physiol 1959;14: 84-8.

2. Shorten GD, Opie NJ, Graziotti P, Morris I, Khangure M. Assessment of upper airway anatomy in awake, sedated and anaesthetised patients using magnetic resonance imaging. Anaesth Intensive Care 1994;22:165-9.

3. Mathru M, Esch O, Lang J, et al. Magnetic resonance imaging of the upper airway. Effects of propofol anesthesia and nasal continuous positive airway pressure in humans. Anesthesiology 1996;84:273-9.

4. Elam JO, Greene DG, Schneider MA, et al. Head-tilt method of oral resuscitation. J Am Med Assoc 1960;172:812-5.

5. Ruben HM, Elam JO, Ruben AM, Greene DG. Investigation of upper airway problems in resuscitation. 1. Studies of pharyngeal $x$-rays and performance by laymen. Anesthesiology $1961 ; 22: 271-9$.

6. Uzun L, Ugur MB, Altunkaya H, Ozer Y, Ozkocak I, Demirel CB. Effectiveness of the jaw-thrust maneuver in opening the airway: a flexible fiberoptic endoscopic study. ORL J Otorhinolaryngol Relat Spec 2005;67:39-44.

7. Roth B, Magnusson J, Johansson I, Holmberg S, Westrin P.
Jaw lift: a simple and effective method to open the airway in children. Resuscitation 1998;39:171-4.

8. Zideman DA, De Buck ED, Singletary EM, et al. European Resuscitation Council guidelines for resuscitation 2015 section 9: first aid. Resuscitation 2015;95:278-87.

9. Perkins GD, Handley AJ, Koster RW, et al. European Resuscitation Council guidelines for resuscitation 2015 section 2: adult basic life support and automated external defibrillation. Resuscitation 2015;95:81-99.

10. Kleinman ME, Brennan EE, Goldberger ZD, et al. Part 5: Adult basic life support and cardiopulmonary resuscitation quality. 2015 American Heart Association guidelines update for cardiopulmonary resuscitation and emergency cardiovascular care. Circulation 2015;132(18 Suppl 2):S414-35.

11. World Health Organization, Regional Office for the Western Pacific. The Asia-Pacific perspective: redefining obesity and its treatment. Melbourne: International Diabetes Institute; 2000.

12. Safar P, Escarraga LA, Chang F. Upper airway obstruction in the unconscious patient. J Appl Physiol 1959;14:760-4.

13. Safar P. New data on resuscitation. Trans Am Inst Electr Eng Power Appar Syst 1958;77:781-3.

14. Guildner CW. Resuscitation: opening the airway. A comparative study of techniques for opening an airway obstructed by the tongue. JACEP 1976;5:588-90.

15. American Lung Association. How can I determine a normal peak flow rate for me [Internet]. Chicago, IL: American Lung Association [cited 2018 Mar 19]. Available from: https://www. lung.org/lung-health-and-diseases/lung-disease-lookup/asthma/living-with-asthma/managing-asthma/measuring-yourpeak-flow-rate.html.

16. Size Korea. Size Korea whole body [Internet]. Seongnam: Korean Agency for Technology and Standards; 2015 [cited 2017 Oct 27]. Available from: http://sizekorea.kats.go.kr/03_report/ yearCompare.asp?pageNum $=01$. 